\title{
SIMULASI DISTRIBUSI TEKANAN INJEKSI PADA RESERVOIR MENGGUNAKAN METODE FINITE DIFFERENCE
}

\author{
Jamaluddin $^{1 *}$, Nuruddin Kafy El-Ridlo ${ }^{2}$, Hamriani Ryka ${ }^{1}$, Maria $^{3}$ \\ ${ }^{1}$ Program Studi Teknik Geologi, Sekolah Tinggi Teknologi Migas Balikpapan, Indonesia. \\ ${ }^{2}$ Program Studi Teknik Perminyakan, Sekolah Tinggi Teknologi Migas Balikpapan, Indonesia. \\ ${ }^{3}$ Departemen Geofisika, Fakultas Matematika dan Ilmu Pengetahuan Alam, Universitas Hasanuddin, Makassar, \\ Indonesia. \\ *Corresponding author. Email: jamaluddin@sttmigas.ac.id
}

Manuscript received: 30 August 2019; Received in revised form: 28 November 2019; Accepted: 11 December 2019

\begin{abstract}
Abstrak
Pemodelan persebaran tekanan injeksi reservoir sangat penting dilakukan untuk mengetahui manajemen reservoir, terutama pada memperkirakan mekanisme pendorongan. Pemodelan distribusi tekanan injeksi reservoir dilakukan dengan menerapkan persamaan analitik aliran fluida pada media berpori dari Hukum Darcy dan ditransformasikan ke persamaan numerik finite difference yang kemudian menggunakan Neumann boundary conditions. Adapun parameter yang digunakan dalam pemodelan tersebut antara lain: permeabilitas, ketebalan lapisan rata-rata, porositas, percepatan gravitasi, viskositas, dan luas daerah. Berdasarkan hasil pemodelan, daerah distribusi tekanan injeksi semakin menurun setiap adanya peningkatan laju tekanan injeksi. Penurunan ini terjadi akibat adanya ketidakseimbangan antara volume fluida reservoir yang dihasilkan dengan volume air dari aquifer yang menggantikan pada reservoir tersebut sehingga terjadi pengosongan. Dari hasil pemodelan tersebut dapat diketahui jumlah produksi minyak yang diperoleh dari cadangan minyak sisa terhadap perolehan minyak mula-mula di reservoir setelah dilakukan proses pressure maintenance.
\end{abstract}

Kata kunci: Hukum Darcy; finite difference; reservoir; simulasi; tekanan injeksi.

\begin{abstract}
The modeling of reservoir injection pressure distribution is very important to perceive reservoir management, especially in estimating the pushing mechanism. The modeling of reservoir injection pressure distribution was carried out by applying the analytic equation of fluid flow to the porous media of Darcy's law and transformed to a finite difference numerical equation which then used Neumann boundary conditions. The parameters used in the modeling were: permeability, average layer thickness, porosity, acceleration of gravity, viscosity, and area's width. Based on the results of modeling, the injection pressure distribution area decreased as injection pressure rate increased. This decrease occurred due to an imbalance between the volume of reservoir fluid produced by the volume of water from the aquifer that replaced the reservoir, caused emptying. From the results of the modelling the amount of oil production, obtained from the remaining oil reserves to the initial oil acquisition in the reservoir after the process of pressure maintenance, could be found.
\end{abstract}

Keywords: Darcy's law; finite difference; injection pressure; reservoir; simulation. 


\section{Pendahuluan}

Dalam industri minyak dan gas, pemodelan reservoir sangat penting untuk dilakukan sebagai tahap awal yang bertujuan meningkatkan estimasi cadangan dan membuat keputusan mengenai pengembangan lapangan, memprediksi produksi di masa depan, menempatkan sumur tambahan, dan membuat rancangan skenario pengelolaan reservoir.

Batuan reservoir adalah batuan bawah permukaan yang mampu menjadi perangkap gas, minyak, air dan fluida reservoir lainnya sehingga dibutuhkan suatu metode yang dapat mengalirkan fluida tersebut ke lubang sumur untuk kemudian diangkat ke permukaan (Essley, 1965).

Reservoir fluida terdiri dari batuan yang berongga atau berpori, fluida akan mengalir melalui pori-pori batuan tersebut. Aliran fluida dipengaruhi oleh sifat - sifat batuan reservoir dan sifat fluida pada reservoir (Dake, 1994).

Ada beberapa tujuan dilakukan pemodelan dan simulasi dalam manajemen reservoir, antara lain sebagai berikut (Craft dan Hawkins, 1991):

1. Mengidentifikasi dan mendefinisikan suatu reservoir;

2. Menentukan sifat - sifat fisik reservoir;

3. Memperkirakan mekanisme pendorongan;

4. Memperkirakan kinerja reservoir;

5. Menentukan jumlah minyak dan tingkat perolehan; dan

6. Menentukan kontrol operasi dan waktu yang tepat.

Pemodelan reservoir dilakukan dengan mengambil bentuk geometri reservoir. Dengan menerapkan persamaan analitik aliran fluida pada media berpori dari Hukum Darcy dan ditransformasikan ke persamaan numerik finite difference yang kemudian menggunakan Neumann boundary conditions. Persamaan Hukum Darcy menjadi faktor utama dalam simulasi ini (Bear dan Bachmat, 1991).

Penelitian ini bertujuan untuk mengetahui sebaran distribusi tekanan injeksi aliran fluida sehingga dapat berperan dalam membuat keputusan sebelum dilakukan pengeboran. Hal ini dilakukan untuk meminimalisir biaya produksi.

\section{Tinjauan Pustaka}

Untuk memodelkan reservoir minyak dan gas bumi maka dibutuhkan persamaan yang terkait dengan keadaan reservoir. Darcy menemukan bahwa kecepatan alir fluida di dalam suatu medium berbanding lurus dengan gradien tekanan dan karakteristik dari media berpori. Karakteristik media tersebut dinyatakan dengan $k$, yang menggambarkan kemampuan media tersebut untuk mengalirkan fluida seperti terlihat pada persamaan (1) (Bear dan Bachmat, 1991).

$$
Q=-\frac{k A}{\mu} \nabla P_{h}
$$

dengan,

$Q \quad$ : total debit dalam satuan volume per detik $\left(\mathrm{m}^{3} / \mathrm{s}\right)$

$\nabla P_{h}$ : perubahan tekanan $\left(\mathrm{Pa} \mathrm{m}^{-1}\right)$

$\mu \quad$ : viskositas (Pa s)

$k$ : permeabilitas $(\mathrm{mD})$

$A \quad$ : satuan luas $\left(\mathrm{m}^{2}\right)$

Metode finite difference adalah merupakan salah satu bentuk metode numerik yang dapat digunakan untuk memecahkan dan menyelesaikan suatu persamaan diferensial secara diskrit untuk persamaan persamaan diferensial parsial yang sulit atau tidak bisa diselesaikan secara analitik (Chaudry, 2008).

Konsep dasar yang digunakan dalam metode finite difference adalah membentuk petak - petak (grid) yang digunakan sebagai acuan untuk 
menemukan solusi pada koordinat parameter yang diuji, yang disimbolkan sebagai titik pada petak - petak (grid) tersebut. Suatu fungsi dari suatu variabel bebas $f$ dan dapat diturunkan hingga $n$ kali didalam interval $\left[x_{0}-h_{1} x_{0}+h_{0}\right]$ dimana $x$ cukup kecil sehingga dapat diuraikan dalam bentuk deret teorema Taylor sebagai berikut:

$$
\begin{gathered}
f\left(x_{0}+h\right)=f\left(x_{0}\right)+h f^{\prime}\left(x_{0}\right)+\frac{h^{2}}{2 !} f^{\prime \prime}\left(x_{0}\right)+ \\
\ldots+\frac{h^{n}}{n !} f^{n}\left(x_{0}\right) \\
f\left(x_{0}-h\right)=f\left(x_{0}\right)-h f^{\prime}\left(x_{0}\right)+\frac{h^{2}}{2 !} f^{\prime \prime}\left(x_{0}\right)- \\
\ldots+(-1) \frac{h^{n}}{n !} f^{n}\left(x_{0}\right)
\end{gathered}
$$

Persamaan (2) dan (3) diatur kembali sehingga diperoleh:

$$
\begin{aligned}
\frac{d f\left(x_{0}\right)}{d x}= & \frac{f\left(x_{0}+h\right)-f\left(x_{0}\right)}{h}-\frac{h}{2 !} f^{\prime \prime}\left(x_{0}\right) \\
& -\cdots-\frac{h^{n-1}}{n !} f^{n}\left(x_{0}\right)
\end{aligned}
$$

$$
\begin{aligned}
\frac{d f\left(x_{0}\right)}{d x}= & \frac{f\left(x_{0}\right)-f\left(x_{0}-h\right)}{h}+\frac{h}{2 !} f^{\prime \prime}\left(x_{0}\right) \\
& -\cdots-(-1) \frac{h^{n-1}}{n !} f^{n}\left(x_{0}\right)
\end{aligned}
$$

Pendekatan turunan pertama $f(x)$ di titik $x_{0}$, maka persamaan (4) dan (5) menjadi :

$$
\begin{aligned}
& \frac{d f\left(x_{0}\right)}{d x} \approx \frac{f\left(x_{0}+h\right)-f\left(x_{0}\right)}{h} \\
& \frac{d f\left(x_{0}\right)}{d x} \approx \frac{f\left(x_{0}\right)-f\left(x_{0}-h\right)}{h}
\end{aligned}
$$

Menggunakan persamaan (4) dan (5) digunakan untuk memperoleh bentuk pendekatan turunan pertama yang lain, yaitu pendekatan beda maju (forward difference):

$$
\frac{d f\left(x_{0}\right) \approx}{d x} \frac{f\left(x_{0}+h\right)-f\left(x_{0}\right)}{h}
$$

\section{Metode Penelitian}

Penelitian dilakukan dengan menerapkan Hukum Darcy. Persamaan analitik aliran fluida pada media berpori dari Hukum Darcy ditransformasikan kepersamaan numerik finite difference yang kemudian menggunakan Neumann boundary conditions. Penelitian ini memodelkan suatu area dengan ukuran $30 \mathrm{~km}$ x $30 \mathrm{~km}$. Adapun beberapa parameter yang digunakan untuk memodelkan reservoir minyak bumi yaitu permeabilitas, porositas, dan viskositas dan laju tekanan injeksi. Keuntungan dari metode finite difference seperti yang dinyatakan oleh Abbas F (2000) meliputi kesederhanaan, kemudahan perpanjangan dari $1 \mathrm{D}$ ke $2 \mathrm{D}$ dan 3D, dan kompatibilitasnya dengan aspek fisika dari aliran dua dan tiga fasa. Hukum Darcy pada 2D menjadi:

$$
\begin{gathered}
\left(v_{x}+v_{y}\right)=\nabla\left(-\frac{k}{n \mu}\left(\frac{\partial P_{h}}{\partial x}-\frac{\partial P_{h}}{\partial y}\right)\right) \\
\left(v_{x}+v_{y}\right)=-\frac{k}{n \mu}\left(\frac{\partial^{2} P_{h}}{\partial x^{2}}-\frac{\partial^{2} P_{h}}{\partial y^{2}}\right) \\
-k\left(\frac{\partial^{2} P_{h}}{\partial x^{2}}-\frac{\partial^{2} P_{h}}{\partial y^{2}}\right)=R
\end{gathered}
$$

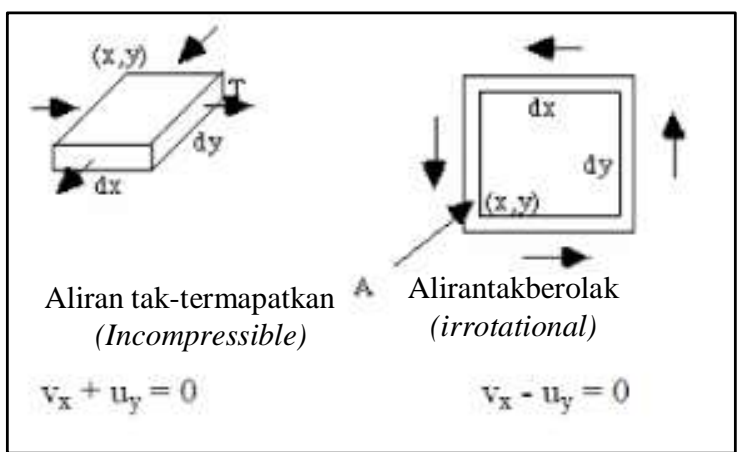

Gambar 1. Aliran fluida tak-termapatkan (incompressible) dan aliran tak berolak (irrotational)

Berdasarkan gambar 1, persamaan aliran fluida yang keluar dari suatu volume:

$$
\begin{gathered}
d x d y V=\rho V d y(v(x+d x, y)-v(x, y)) d t+ \\
\rho V d x(v(x, y+d y)-v(x, y)) d t
\end{gathered}
$$


nilai $d x d y d V=0, \quad$ persamaan

merupakan aliran fluida pada system fluida tak-termapatkan (incompressible)

$$
\rho\left(v_{x}+v_{y}\right)=\rho\left(\frac{\partial v}{\partial x}+\frac{\partial v}{\partial y}\right)=0
$$

Aliran fluida saat tidak ada sirkulasi atau rotasi dapat dijelaskan dengan curl kecepatan. Curl 2D $(u, v)$ adalah $v_{x}-v_{y}$. Volume $d x d y T$ pada luasan $\mathrm{A}$ dan densitas $\rho$

$$
\begin{aligned}
& \rho A d y(y(x+d x, y)-v(x, y)) d t+ \\
& \rho A d x(v(x, y+d y)-v(x, y)) d t
\end{aligned}
$$

Keadaan irrotasi $d x d y V=0$, persamaan (14) menjadi

$$
\rho\left(v_{x}+v_{y}\right)=\rho\left(\frac{\partial v}{\partial x}+\frac{\partial v}{\partial y}\right)=0
$$

Nilai R:

$$
R=\rho\left(\frac{\partial x}{\partial t}-\frac{\partial y}{\partial t}\right)
$$

Subtitusi persamaan (16) ke (11):

$$
\begin{gathered}
-K\left(\frac{\partial^{2} P_{h}}{\partial x^{2}}-\frac{\partial^{2} P_{h}}{\partial y^{2}}\right)=\rho\left(\frac{\partial x}{\partial t}-\frac{\partial y}{\partial t}\right) \\
\frac{\partial x}{\partial t}=-\frac{K}{\rho}\left(\frac{\partial^{2} P}{\partial x^{2}}-\frac{\partial^{2} P}{\partial y^{2}}\right)+\frac{\partial y}{\partial t}
\end{gathered}
$$

\section{Hasil dan Pembahasan}

Data yang dibutuhkan untuk melakukan simulasi dapat diperoleh dari berbagai sumber data yang memungkinkan. Pemilihan sumber data serta pengolahan juga sangat berpengaruh terhadap kesiapan data itu sendiri, yang pada akhirnya juga berpengaruh terhadap hasil simulasi secara keseluruhan. Ada pun data yang digunakan dalam pemodelan tersebut adalah sebagai berikut:
Tabel 1. Parameter fisik reservoir.

\begin{tabular}{cc}
\hline Parameter fisik & Nilai \\
\hline Permeabilitas $(\mathrm{K})$ & $10 \mathrm{mD}$ \\
\hline $\begin{array}{c}\text { Ketebalan Lapisan } \\
\text { rata-rata }(\mathrm{h})\end{array}$ & $100 \mathrm{ft}$ \\
\hline Porositas $(\Phi)$ & $25 \%$ \\
\hline Konstanta gravitasi $(\mathrm{g})$ & $9.8 \mathrm{~m} / \mathrm{s}^{2}$ \\
\hline Viskositas $(\mu)$ & $6.27 \times 10^{-14} \mathrm{~Pa} . \mathrm{s}$ \\
\hline Luas daerah $(\mathrm{A})$ & $(30,30) \mathrm{Km}$ \\
\hline
\end{tabular}

Minyak dan gas bumi yang berada di dalam reservoir bergerak menuju lubang sumur akibat beberapa proses baik proses alamiah maupun buatan. Proses buatan dapat berupa pendorongan melalui injeksi di sumur lain yaitu pemberian tenaga dorong tambahan. Proses alamiah dapat diakibatkan oleh (a) ekspansi fluida, (b) pendorongan fluida, (c) gravitasi, dan (d) keadaan kapilaritas.

Ketika laju tekanan injeksi yang diberikan sebesar 1000 ton, maka area sebaran laju tekanan injeksi juga semakin luas maka kecepatan fluida yang mengalirakan lebih besar pula melalui media yang berpori akan tetapi daerah distribusi laju tekanan injeksi akan semakin kecil atau distribusi tekanan mengalami penurunan ketika tekanan injeksi juga mengalami peningkatan (Gambar 2). Penurunan ini terjadi akibat adanya ketidakseimbangan antara volume fluida reservoir yang dihasilkan dengan volume air dari akuifer yang menggantikan pada reservoir tersebut sehingga terjadi pengosongan (Kristanto, 2015).

Prinsip dasar mekanika fluida dari media berpori adalah bahwa vektor kecepatan makroskopik fluida selalu normal terhadap permukaan ekuipotensial dan besarnya vektor ini berbanding lurus dengan gradien potensial. Karena distribusi potensial didalam fluida menentukan kecepatan makroskopis fluida dan juga keseluruhan aliran. Apabila terjadi penurunan tekanan reservoir, biasanya gas yang terlarut akan terbebaskan dari minyak, dan akan membentuk free gas di dalam reservoir. 

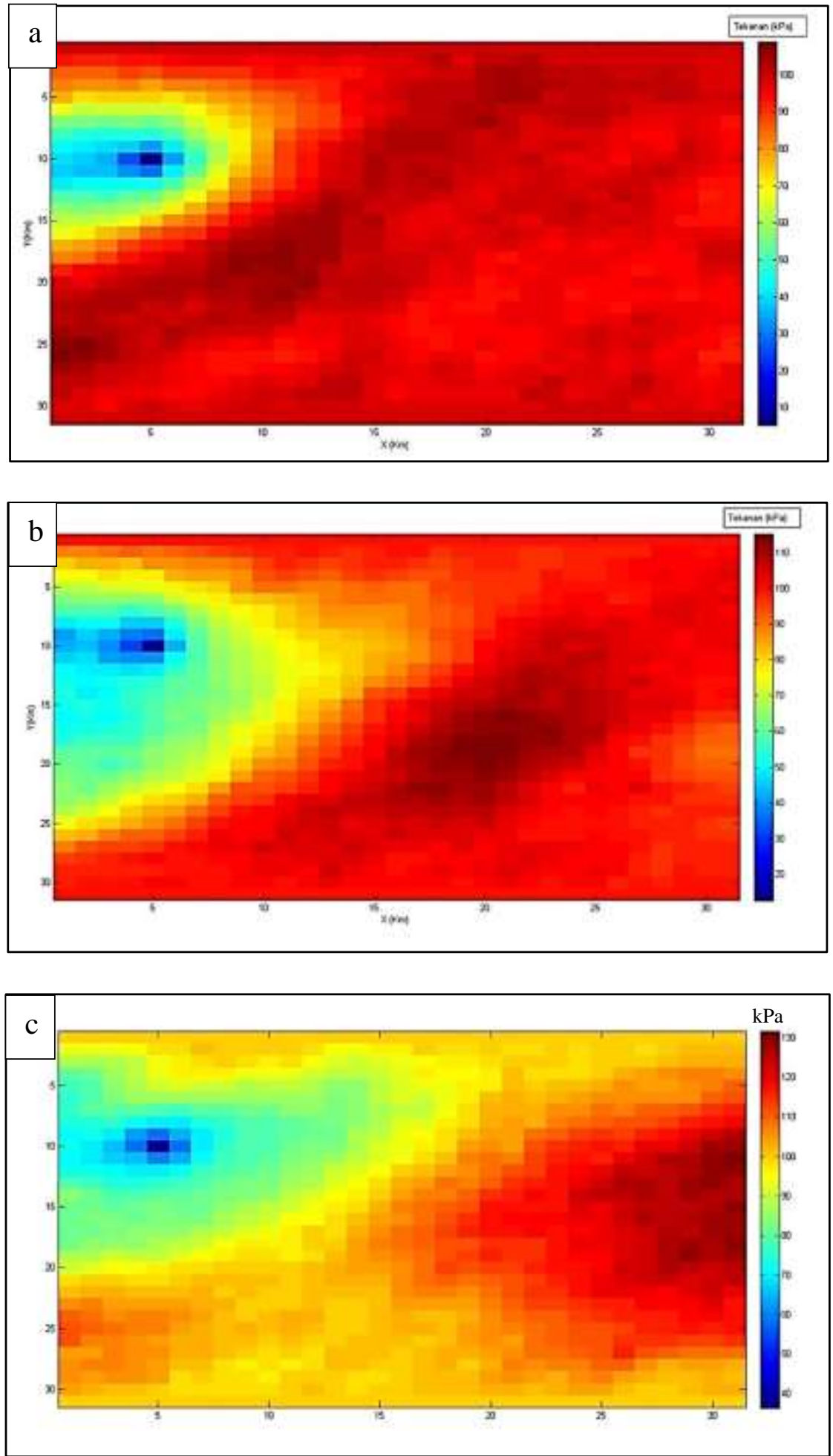

Gambar 2. Sebaran tekanan pada area (30, 30) km dengan laju tekanan injeksi (a). 1000 ton, (b). 5000 ton, (c) 10.000 ton.

Berdasarkan penelitian yang telah dilakukan oleh Ermawati (2018), simulasi distribusi tekanan hidrolik berdasarkan Hukum Darcy yang diterapkan pada suatu pemodelan reservoir, ada beberapa asumsi yang diterapkan seperti incompressible dan irrotational untuk menyederhanakan suatu pemodelan reservoir. Pemodelan reservoir suatu lapangan itu sangat bervariasi tergantung dari kondisi daerah lapangan tersebut. 
Ada beberapa yang harus diperhatikan dalam penentuan pola sumur injeksi produksi seperti:

a) Tingkat keseragaman formasi, yaitu penyebaran permeabilitas kearah lateral maupun kearah vertikal;

b) Struktur batuan reservoir meliputi patahan, kemiringan, dan ukuran;

c) Sumur-sumur yang sudah ada (lokasi dan penyebaran);

d) Topografi;

e) Ekonomi;

\section{Kesimpulan}

Berdasarkan hasil pemodelan yang telah dilakukan pada suatu reservoir dengan dengan laju tekanan injeksi 1000 ton, 5000 ton, dan 10.000 ton. Dalam pemodelan tersebut, distribusi tekanan injeksi semakin menurun disetiap peningkatan laju tekanan injeksi dan luasan distribusi tekanan tersebut semakin berkurang. Apabila terjadi penurunan tekanan reservoir, biasanya gas yang terlarut akan terbebaskan dari minyak, dan akan membentuk free gas di dalam reservoir.

\section{Daftar Pustaka}

Abbas, F. 2000. Thermodynamics of Hydrocarbon Reservoirs. Mc GrawHill.

Bear, J. dan Bachmat, Y. 1991. Introduction to Modeling of Transport Phenomena in Porous Media. Dordrecht (NL): Kluwer Academic Publisher.

Chaudry, M.H. 2008. Open-Channel Flow. $2^{\text {nd }}$ ed., Springer, New York, NY.

Craft, B.C., Hawkins, M. 1991. Applied Petroleum Reservoir Engineering. Revised by Terry R.E., Prentice Hall, Englewood Cliffts, NJ.

Dake, L.P. 1994. The practice of Reservoir Engineering. Elsevier Science B.V., Amsterdam: Netherlands.

Ermawati, E. 2018. Solusi numerik Pemodelan Reservoir 2 Dimensi
Menggunakan Metode Finite Difference. Skripsi. IPB.

Essley, P. L. Jr. 1965. What is reservoir engineering. Journal of Petroleum Technology.

Kristanto, D. 2015. Evaluasi penggunaan injeksi air untuk pressure maintenance pada reservoir lapangan minyak. Skripsi. UPN Veteran Yogyakarta. 